\title{
Neoliberalismo y masculinidad en Nostalgia de la Sombra, de Eduardo Antonio Parra
}

\author{
Neoliberalism and masculinity in Nostalgia de la Sombra, \\ by Eduardo Antonio Parra
}

\author{
SABINO LUÉVANO \\ ORCID: https://orcid.org/0000-0003-4631-4278 \\ Millsaps College, Estados Unidos \\ salueva26@gmail.com
}

Resumen:

Este artículo tiene como objetivo estudiar la representación de la masculinidad en la novela Nostalgia de la sombra (2002), de Eduardo Antonio Parra. A partir del diálogo con teorías de masculinidad, neoliberalismo, vulnerabilidad y estudios culturales latinoamericanos contemporáneos, este ensayo analiza cómo el protagonista de Nostalgia se inserta en un imaginario cultural específico y en diferentes discursos sociales sobre lo que significa ser hombre en México. En el contexto actual de violencia que vive el país, este análisis busca señalar las lógicas de poder que trajo la imposición del neoliberalismo y cómo es que hacen posibles diferentes fenómenos de necroempoderamiento masculino.

Palabras clave:

masculinidad hegemónica, género, violencia objetiva, neoliberalismo, capitalismo gore. 


\section{Abstract:}

This article aims to study the representation of masculinity in the novel Nostalgia de la sombra (2002), by Eduardo Antonio Parra. By establishing a dialogue with theories of masculinity, neoliberalism, vulnerability and contemporary Latin American cultural studies, this essay analyzes the way in which the main character of Nostalgia is inserted in a specific cultural imaginary and in different social discourses about what it means to be a man in Mexico. In the present context of violence that the country is experiencing, this analysis seeks to point out certain practices of power brought forth by the imposition of neoliberalism and how they trigger different phenomena of masculine necro-empowerment.

Key words:

hegemonic masculinity, sovereign masculinity, objective violence, neoliberalism, gore capitalism.

Recibido: 17 de diciembre de 2020 Aceptado: 15 de agosto de 2021 DOI: https://doi.org/10.36798/critlit.v0i24.373

\section{INTRODUCCIÓN}

Nostalgia de la Sombra (2002) fue la primera novela del escritor regiomontano Eduardo Antonio Parra, quien era conocido hasta ese momento por sus libros de cuentos El río, el pozo y otras fronteras (1995), Los límites de la noche (1996) y Tierra de nadie (1999). La novela está escrita en un lenguaje contemplativo — con reminiscencias de Knut Hamsun, William Faulkner y Juan Rulfo-, privilegia y espacia la subjetividad psicológica y el monólogo interior, y se estructura en dos tiempos narrativos - el presente y el recuerdo-. Nostalgia de la sombra 
cuenta la historia de Bernardo, un corrector de estilo en uno de los periódicos de Monterrey que, luego de defenderse de un asalto y matar a los agresores, descubre su gusto por la sangre, abandona a su familia y se embarca en una odisea que lo lleva a vivir primero como vagabundo en un basurero, después a la prisión y finalmente a trabajar como sicario profesional para Damián, un poderoso empresario que se dedica a eliminar enemigos de sus clientes.

El análisis de la novela que este artículo propone se centra principalmente en el problema de la masculinidad que encarna el personaje protagónico. Este fenómeno ha sido poco explorado por la crítica. A través de cuatro apartados contenidos en este trabajo, se explorarán cuatro capas de la representación de la masculinidad en Bernardo. El artículo iniciará con un análisis del espacio de la cantina, un escenario importante de convivencia homosocial en el imaginario cultural mexicano, con una fuerte presencia sobre todo en las narrativas visuales clásicas del cine nacional, que lo presentaban con rasgos comunitarios y utópicos. En Nostalgia de la sombra la cantina rompe con este esquema de representación comunitaria al explorar formas violentas de convivencia que vulneran el tejido social. El segundo apartado explora cómo el neoliberalismo mexicano ha generado nuevas subjetividades masculinas que reproducen sus puntales ideológicos, como la depredación y —en su versión más extrema- el asesinato. Esta rabia machista, sin embargo, por un lado reafirma la lógica neoliberal, pero por el otro, soterra condiciones de vulnerabilidad e inestabilidad de género primarias del sujeto masculino — siendo la violencia su estrategia de reafirmación performativa-, tema que exploran los últimos dos apartados. La tesis de este artículo postula que Bernardo, a pesar de inscribirse en códigos de comportamiento criminales y violentos, es un personaje ambivalente, víctima y verdugo, cuyas acciones se pueden comprender a partir de representaciones y discursos culturales sobre lo que significa ser hombre en México, así como dentro de la subjetividad masculina predatoria que trajo consigo el neoliberalismo o capitalismo gore. 


\section{IMAGINARIOS CULTURALES DIVERGENTES EN EL ESPACIO HOMOSOCIAL DE LA CANTINA}

La primera acción de Nostalgia de la sombra transcurre en una cantina de la Ciudad de México, donde Bernardo recibe el encargo de Damián, su patrón, de asesinar a Maricruz Escobedo, una empresaria de Monterrey. La selección de este espacio no es gratuita, ya que en el imaginario cultural mexicano la cantina ha sido, históricamente, uno de los lugares privilegiados de convivencia masculina. ${ }^{1}$ En el cine de la Época de Oro de los años cuarenta y cincuenta, por ejemplo, "la cantina es el santuario de la comunión machista" (Ríos Gascón 81). En esta época las mujeres no eran admitidas en las cantinas, por lo que estos espacios eran territorio masculino exclusivo en donde se reforzaba un performance de género machista. Carlos Monsiváis va un paso más allá que Gascón al afirmar que en la cantina del cine de la Época de Oro "el carácter masculino [mexicano] fue forjado" (118). Y si la masculinidad, como argumenta Robert Irwin "is often achieved through certain competitive or ritual acts" (xxi), en la cantina los actos rituales de género eran constituidos por el juego, la cercanía con el otro, la charla, la borrachera compartida, las peleas, las confesiones y la fiesta amenizada por canciones de desamor.

Un tópico significativo que permeaba y codificaba este espacio —especialmente en las películas estelarizadas por Pedro Infante-, como bien argumenta Sergio De la Mora en Cinemachismo (2006), era el de la amistad masculina, lazo afectivo que a veces rayaba en un homoerotismo vedado (97), como en la película $A$ toda máquina

${ }^{1}$ Algunos trabajos que analizan el rol de la cantina y espacios similares en el cine mexicano son Cinemachismo (2006) de Sergio de la Mora, Screening neoliberalism (2014) de Ignacio Sánchez Prado, Performing mexicanidad (2010) de Laura G. Gutiérrez, El cine de Carlos Fuentes (2017) de Iván Ríos Gascón, Los bajos fondos (1989) de Sergio Gónzalez Rodríguez, entre otros. 
(1954), de Ismael Rodríguez, donde Pedro y Luis constantemente se sabotean las novias, comportamiento que De La Mora interpreta como un claro deseo homosexual inconsciente.

La cantina funcionaba, pues, como un territorio ideal para el performance de una masculinidad machista y heteronormativa, pero al mismo tiempo proyectaba un carácter utópico y comunitario. Estas representaciones culturales fueron posibles, en gran medida, gracias a la influencia cultural de la Revolución mexicana y su promoción de la armonía y el derecho de las masas a la participación plena en la nación. La masa, hasta entonces anónima y marginal, se integra y transforma lentamente en sociedad (Barbero 172). A diferencia del porfiriato, constituido por jerarquías sociales casi inamovibles, la Revolución mexicana sí generó mecanismos, si bien imperfectos, problemáticos y posteriormente pervertidos, de movilidad e integración social que beneficiaron a millones de campesinos, siendo que en ese período histórico la mayoría de los mexicanos vivía en el campo. ${ }^{2}$ Durante los primeros veinte años de la Revolución mexicana, los gobiernos del bando vencedor diseñaron uno de los modelos sociales comparativamente más exitosos en América Latina. Este modelo se sustentaba en una serie de complejos componentes políticos que contribuyeron a la consolidación de lo que Lorenzo Meyer llamó "una isla de paz en el caótico mundo político latinoamericano" (113). Paulatinamente, debido a las contradicciones internas del régimen, a la demanda ciu-

${ }^{2}$ A pesar de las significativas discrepancias entre los historiadores contemporáneos sobre el alcance, repercusiones, rupturas y significado de la Revolución mexicana y sus personajes, la mayoría concuerda en que en el México post-revolucionario hubo mayor igualdad social. Algunos trabajos importantes que lo comentan son La revolución mexicana (2012) de Alan Knight, Zapata (1968) de John Womack (1968), The Life and Times of Pancho Villa (1998) de Friedrich Katz, El Cardenismo, una utopia mexicana (1994) de Adolfo Gilly, Revolutionary Women in Postrevolutionary Mexico (2005) de Jocelyn Olcott, Cárdenas Compromised (2001) de Ben Fallaw, entre otros. 
dadana por una democracia auténtica y a un contexto internacional marcado por el fin de la utopía socialista, el modelo entró en crisis, situación que aprovechó la facción de derecha del PRI, con apoyo del PAN, para imponer el modelo neoliberal. En este nuevo paradigma y contexto socioeconómicos, las representaciones culturales son informadas por nuevas sensibilidades y experiencias sociales.

Nostalgia de la sombra es uno de los muchos artefactos culturales contemporáneos que registran los cambios en el imaginario mexicano con respecto a la transformación de la masculinidad a través del manejo de espacios icónicos como la cantina. Esta, de su antigua aura utópica y homosocial, deviene en la novela en un sitio de jerarquías donde, más que gestos fundacionales de hermandad entre hombres, se conciben planes criminales que fragmentan la comunidad y la nación. Las dos representaciones de la cantina y sus contextos no pueden ser más contrastantes. Mientras que el primero funcionaba como una metáfora de la nueva nación mexicana en donde se exaltaba la hermandad y la camaradería — a la par que el machismo-, en el segundo, la relación que se establece entre Bernardo y su patrón es informada por el ethos neoliberal contemporáneo, caracterizado por una relación violenta entre hombres de negocios y trabajadores. La novela describe a Damián como un hombre privilegiado, perteneciente a la élite capitalista mexicana que abrazó e impuso con absoluto fanatismo el paradigma neoliberal en los años ochenta y noventa:

Tras largas meditaciones dedujo que Damián pertenecía a una de las familias poderosas del país, aunque no contaba con acceso directo a los niveles superiores. A través de comentarios sueltos se enteró de que, luego de realizar un doctorado en Chicago, donde fue condiscípulo de varios políticos mexicanos, regresó al país lleno de ambiciones. (16)

La referencia a Chicago, el centro neurálgico de la doctrina económica neoliberal, deja en claro lo que representa Damián: el empresario de derecha latinoamericano por excelencia, que combina $-\mathrm{y}$ 
distorsiona - la doctrina económica de Milton Friedman y otros economistas conservadores con el autoritarismo y la corrupción propios de las élites latinoamericanas. Bernardo, en cambio, ocuparía el otro extremo de la pirámide social en cuanto a su estatus económico: uno de los tantos millones de hombres mexicanos en constante estado de precariedad económica, que conforman la mayor parte de la fuerza laboral del país. ${ }^{3}$

El hecho de que una de las empresas de Damián se dedique al sicariato selectivo contra empresarios o políticos prominentes, posibilita la deconstrucción crítica del discurso oficial que concibe la génesis y práctica de la violencia del crimen organizado como exclusiva de los sectores económicamente más desfavorecidos o como un "otro" exterior al Estado y a la ciudadanía. En su lugar, Nostalgia de la sombra no solo explora la violencia visible del sicario, sino también la otra violencia, la estructural o ultra objetiva. Este concepto -originalmente de Étiene Balibar-, es redefinido por Zizek como "inherente a las condiciones sociales del capitalismo global y que implica la creación 'automática' de individuos desechables y excluidos, desde los sintecho a los desempleados" (25). En otras palabras,

${ }^{3} \mathrm{Si}$ se revisan las cifras que proporcionó Viri Ríos en el 2020, basada en datos del INEGI del mismo año, se puede concluir que la mayor parte de la población ocupada en México, con o sin educación, pertenece a la clase baja, a pesar de la autopercepción de la mayoría de los mexicanos de pertenecer a la clase media. El problema del artículo de Ríos, es que no elabora divisiones dentro de las clases, por ejemplo; clase media baja, media alta, etc. En su lugar utiliza estas tres categorías -clase baja, clase media y clase alta- como jerarquías definitivas, de tal forma que, para Ríos, para ser de clase media en México es necesario tener un ingreso de 64 mil pesos mensuales para una familia de 4, cifra un tanto exagerada, ya ese es el promedio de salarios en Estados Unidos. Pero dado que estos son los datos arrojados por los especialistas y por el INEGI, se asumirá que Ramiro es de clase baja, como la mayoría de los mexicanos, y por lo tanto representa al hombre común mexicano. Ver: "No, no eres clase media" de Viri Ríos. 
la condición de posibilidad de la violencia urbana visible o subjetiva es la violencia sistémica, que emana del centro neurálgico del capital mismo en alianza con el crimen organizado, las altas burocracias, los políticos, los organismos de seguridad y otras complicidades, analizadas hasta el hartazgo por periodistas, cronistas, estudiosos de la literatura y expertos en seguridad nacional como Lolita Bosch, Moisés Naím, Dawn Paley, Héctor Domínguez Ruvalcaba, Oswaldo Zavala, Edgardo Buscaglia, entre otros. Todos estos autores han dejado claro que el crimen organizado no puede operar sin el apoyo del Estado y la clase capitalista. De ahí que no se pueda entender una violencia sin tomar en cuenta a la otra.

En palabras de Héctor Domínguez Ruvalcaba, en México existe una cultura política "donde la intervención de lo criminal es reincidente, de manera que la historia de México no se puede concebir sin las prácticas ilícitas de las autoridades de la clase política y, consecuentemente, de amplios sectores de la sociedad" (8). Nostalgia de la sombra escapa, venturosamente, de la trampa de centrarse solo en la violencia subjetiva individual sin establecer una conexión con la violencia sistémica que, en gran medida, determina a la primera o, por lo menos, sienta las bases para que surja. En otras palabras, para que existan Bernardos, tienen que existir Damianes. Damián es la condición de posibilidad de la violencia de Bernardo, ya que el empresario representa la estructura económica desigual, y Bernardo solo funciona como un pequeño engranaje de una maquinaria social atrofiada, la cual beneficia sobre todo a una élite, y promueve la acumulación de capital desmedida, a través de estrategias necropolíticas que implican el dominio y muerte de un amplio sector de la población. En consecuencia, existe entre ambos personajes una frontera infranqueable, informada por el abismo de clase que los separa, la cual cancela cualquier posibilidad de amistad y convivencia homosocial, evento fundamental en la construcción de la nación desde el siglo XIX.

En las sociedades patriarcales occidentales, históricamente, los lazos homosociales han jugado un papel esencial en la construcción 
nacional. Anterior a la uniformidad lingüística, racial, cultural o étnica, existe un lazo que centra y da por hecho al sujeto masculino como fuente organizadora de la nueva comunidad nacional. En este sentido, el fenómeno de la amistad sería el aceite que lubrica los lazos homosociales dándoles fluidez. Derrida comenta que históricamente la amistad ha sido pensada en la tradición occidental, desde Aristóteles hasta Kant, como una relación fraternal entre hombres que ha privilegiado la figura del hermano sobre la del padre (384). Así, los hombres se asumen como hermanos que defienden a la patria, signada como femenina. En la fundación de las naciones modernas, por lo tanto, la amistad homoscial es imperativa; un puñado de hombres, que se asumen como iguales, fundan simbólica y legalmente la nación. Este acto fundacional impactó el subconsciente del cine de la Época de Oro al emerger la nueva nación postrevolucionaria y sus necesidades narrativas, donde de forma insistente se celebraba la amistad masculina y la homosociabilidad, siendo el espacio de la cantina uno de los lugares privilegiados de convivencia donde los hombres cimentaban alianzas, se consolaban mutuamente y dirimían diferencias. Pero en Nostalgia de la sombra, se invierte el gesto fundacional de convivencia homosocial. Las llamadas por Derrida "políticas de la amistad", entendidas como los códigos que han articulado la relación de hermandad entre hombres, devienen en Nostalgia de la sombra justo su contrario: las políticas de la enemistad fratricida donde los propios hermanos conspiran para matar o se asesinan mutuamente al interiorizar la gramática destructiva del neoliberalismo mexicano, sistema económico que privilegia al individuo sobre las relaciones comunitarias, al capital sobre los derechos humanos, y que busca la reducción y redefinición del Estado, no como garante del bienestar social general, sino como mero policía al mando de los intereses económicos de la clase dominante.

En México, sin embargo, como argumenta Sayak Valencia, el concepto de neoliberalismo es insuficiente para comprender los graves problemas sociales que la adopción, adaptación e imposición de 
esta doctrina económica y social generó en el país. Por tanto, la filósofa tijuanense acuñó el término "capitalismo gore", que considera más ad hoc a la situación mexicana, caracterizada no solo por relaciones económicas desiguales, sino por una violencia desmedida incrustada en la lógica acumulativa de capital. Valencia define el capitalismo gore como:

el derramamiento de sangre explícito e injustificado (como precio a pagar por el Tercer Mundo que se aferra a seguir las lógicas del capitalismo, cada vez más exigentes), al altísimo porcentaje de vísceras y desmembramientos, frecuentemente mezclados con el crimen organizado, el género y los usos predatorios de los cuerpos, todo esto por medio de la violencia más explícita como herramienta de necroempoderamiento. (15)

El capitalismo gore sería la versión impuesta a México (tanto por agentes internos como externos) de la globalización postsoviética, donde el torbellino neoliberal no solo mercantiliza las materias primas, sino también la vida y la muerte, distribuyendo e imponiendo regímenes de vulnerabilidad y lógicas de poder mediante el necroempoderamiento, que es la estrategia última de acumulación de capital mediante la muerte. Si allí está el negocio, como diría Carlos Monsiváis en Los mil y un velorios (1994), dónde se localicen las víctimas es lo de menos (59).

La cantina servirá, en Nostalgia de la sombra, como el espacio de planeación del necroempoderamiento; tanto Damián como Bernardo obtienen dividendos económicos de los asesinatos que llevan a cabo. La muerte es el negocio de Damián, que a su vez recibe órdenes de hombres más poderosos que él que habitan en las sombras. El asesinato no deriva exclusivamente de esta dupla criminal, sino de la estructura sistémica, de las entrañas mismas del capitalismo gore. La cantina, en este contexto, adquiere una significancia radicalmente diferente; pasa de ser antiguo espacio homosocial utópico en el imaginario cultural mexicano, a transformarse en Nostalgia de la sombra 
en el territorio de la distopía. Es pues, la puerta y el presagio de un cambio social extremo en la configuración de la masculinidad, ya que la novela se publicó en el 2002, de un futuro México delirante sumido en la violencia fratricida, producida esta, en gran parte, por la imposición de un modelo que no solo afecta a las estructuras materiales de la sociedad, sino que además crea subjetividades masculinas depredadoras, encargadas de administrar y generar dividendos a través de la muerte.

NADA COMO MATAR A UN HOMBRE O EL TRIUNFO DE LA SUBJETIVIDAD DEPREDADORA

El neoliberalismo, afirma constantemente David Harvey en entrevistas y textos de su autoría, es un proyecto de clase. En efecto, se podría argumentar que el neoliberalismo fue creado por la clase capitalista con la intención de imponer una agenda política concreta, reducir y controlar el papel del Estado, desregularizar el mercado, incrementar sus ganancias a costa de soberanías nacionales o regionales, y defender y mantener sus intereses sobre las mayorías, aunque esto signifique ignorar derechos humanos básicos. Pero el neoliberalismo, yo agregaría, también es un proyecto de género, ya que ha creado y legitimado una subjetividad híper masculina, compuesta por una serie de técnicas de comportamiento masculinistas tales como la agresión, la conquista, la toma de riesgos, la depredación y, sobre todo, el individualismo radical anticomunitario, plasmado en la famosa frase de Margaret Thatcher que afirma que la sociedad no existe (cit. en Nadal). Considero que el personaje de Bernardo se inserta en este imaginario y subjetividad neoliberales y adopta varios de sus componentes ideológicos. Por lo tanto, no concuerdo del todo con Doug P. Bush cuando comenta que Nostalgia puede ser leída, debido a la personalidad semi-anarquista de Bernardo, "as a strong critique and ... rejection of modernity and modernization" (366). Aunque es cierto que la novela en general puede interpretarse como una clara 
deconstrucción del modelo neoliberal en México, no así el personaje de Bernardo. Bush parece equiparar los procesos de modernización de las economías desarrolladas, donde a pesar de las crecientes desigualdades sociales, existe un Estado funcional que protege y garantiza derechos básicos, con la modernización impuesta a los países Latinoamericanos, marcada por la violencia de Estado. El personaje de Bernardo, en un país desarrollado, podría leerse como un personaje rebelde que reniega de la producción capitalista y decide vivir al margen de la ley. En este escenario hipotético, existiría una división más clara entre Estado y criminalidad. En México, en cambio, tomando en cuenta el capitalismo gore que describe Valencia y las reflexiones sobre criminalidad de Domínguez Ruvalcaba, puede decirse que la violencia y el crimen son parte de una lógica de poder que incluye al Estado y sus proyectos de modernidad. En otras palabras, el neoliberalismo, como un proyecto modernizador de Estado, implica violencia. Por un lado, el personaje de Bernardo se puede entender dentro de un contexto social disfórico marcado por los desastres creados por la economía neoliberal (Guzmán 25); pero por el otro, el sicario abraza la lógica depredadora del capitalismo gore. Sus acciones son testimonio avasallante del triunfo de una subjetividad depredadora donde se reifica y fetichiza la conquista, el dominio, la agresión, el riesgo y la falta de escrúpulos. Tanto a hombres de negocios como a narcotraficantes, al fin y al cabo, los mueve el mismo motor ideológico: la ganancia a cualquier costo. ${ }^{4}$ Ambos parten de y encumbran el mito capitalista - tan celebrado en los corridos- del "self-made man" (Valencia 30); hombres que, en teoría, deben su éxito exclusi-

${ }^{4}$ El periodista Moisés Naím menciona en su estupendo estudio sobre las redes criminales contemporáneas, Illicit (2005), que el problema del crimen organizado contemporáneo se radicalizó con la imposición del neoliberalismo, la reducción de los controles de Estado y la desregulación de los mercados, por lo que hay una continuidad orgánica entre empresarios, finanzas globales y narcotráfico. 
vamente a su iniciativa, arrojo, falta de sentimentalismo y fuerza individual, características todas del ethos empresarial machista dominante.

Bernardo es un individualista radical que renuncia a sus obligaciones comunitarias para embarcarse en una odisea criminal, lo cual no lo convierte en un símbolo de crítica a las normas sociales ni al espíritu capitalista de Monterrey, sino más bien en el ejemplo de la reproducción extrema y triunfo de ese ethos que encumbra la ganancia económica por encima de escrúpulos morales y éticos. Se podría incluso afirmar que hay cierta misantropía perversa en el corazón del neoliberalismo. Para Pierre Dardot y Christian Laval, la "norma existencial" del neoliberalismo llama a que las clases trabajadoras se embarquen en una lucha económica darwiniana, al mismo tiempo que justifica la desigualdad e intenta que los individuos se conciban a sí mismos como empresas responsables de su sobrevivencia (3).

Bernardo ha sido conquistado por esta lógica y subjetividad de mercado; él es su propia empresa - un sicario profesional y meticuloso, que se preocupa por hacer bien su trabajo-. A partir de sus elucubraciones solitarias y monólogos interiores, se podría inferir que el personaje concibe el mundo desde ese biologismo spenceriano popular y mal entendido - propio de un amplio sector empresarial- como una selva en la que sobreviven los más fuertes. Para él, los otros hombres son enemigos declarados, ya que considera que todos son culpables de algo. Sus observaciones hostiles hacia los clientes de la cantina, a quienes animaliza con expresiones ofensivas, cancelan cualquier posibilidad de fraternidad: "Uno de los hombres en la barra enronquece al corear la canción, luego lanza un aullido y lo remata con un insulto al aire. Bernardo lo encara por un segundo; enseguida regresa a sus cavilaciones" (12). El protagonista siente un profundo desagrado hacia los hombres borrachos, machistas y lujuriosos que acosan incansablemente a la mesera. No los considera sus pares, y la borrachera compartida, en lugar de generar cierta camaradería propia del consumo de alcohol en las cantinas, parece más bien alejarlo de los demás. Más adelante, cuando observa con mayor 
detenimiento a los parroquianos, se siente feliz al darse cuenta de que un grupo de ladrones acecha a unos borrachos:

en una mesa del fondo como si desesperaran por un trago, cuatro sombras mantienen los ojos fijos en los borrachos que han secuestrado a la mesera. Bernardo sonríe. En cualquier rato les van a dar baje a estos pendejos con la cartera, con el reloj, hasta con los zapatos. Ya los ficharon los compas del rincón. Se lo merecen por idiotas. (13)

Su ojeriza hacia los clientes lo hace reflexionar en lo fácil y placentero que es matar a un hombre. "Nada como matar a un hombre”, es el íncipit de la novela. Y más adelante, Bernardo afirma:

... es tan fácil bajar a los machos de una puñalada o un cuerazo. Dan hueva. Como matar al padre. Eso sí. ¿Por qué no? Sin dificultades. O a un hermano. Lo siento carnal, tengo que borrarte... ¿Y a ti, viejo? Si te contara cada una de las cuerizas, de los regaños, las prohibiciones, las órdenes y los malos tratos a mi madre, no acabaríamos. Y nos parecemos tanto que sería un alivio, igual que romper un espejo, ¿no? (19)

La fantasía del parricidio, común a muchos narcotraficantes y sicarios según García Reyes ("Por qué fracasa la guerra"), es un ejercicio simbólico que busca exorcizar la violencia sufrida y a la vez cerrar el trauma del maltrato paterno. Pero como el autorreconocimiento de la vulnerabilidad se opone al ethos y a la subjetividad híper masculina de Bernardo, el trauma en realidad nunca se cierra, por lo que matar a otros hombres se vuelve una necesidad psicológica recurrente, un rito simbólico de parricidio ad infinitum, casi como una adicción que Bernardo justifica al punto de semi-erotizar el crimen:

Nada como sentir que la sangre de otro nos remoja la piel y quedarnos con su último respiro. Ver cómo boquea, cómo se deshace por hallar un buche de aire que jamás llenará otra vez sus 
pulmones... Sí, medir fuerzas con él. Bocabajearlo. Demostrarle que su vida tiene tanto valor como la del perro al que apedreamos porque se cruzó en nuestro camino. Sin coraje, sin lástima, por el sencillo placer de sentirnos poderosos, capaces de arrancar un pellejo ajeno. (10)

A pesar del intento de Bernardo de escapar de la comunalidad masculina y de su odio por los hombres generado por su ética híper machista y depredadora, ellos forman parte íntima de su campo subjetivo, pero de forma negativa. El crimen es un acto que solo es posible dentro de estructuras complejas de socialización, ya que resulta mandatoria, para que se ejecute, una relación entre un yo y un tú, idea que condensa de forma elocuente Judith Butler en Precarious Life (2004), donde afirma que: "At the most intimate levels, we are social; we are comported toward a 'you'; we are outside ourselves, constituted in cultural norms that precede and exceed us, given over to a set of cultural norms and a field of power that conditions us fundamentally" (45). A pesar de la subjetividad individualista y antisocial que el neoliberalismo posibilita y promueve, el otro siempre nos aguarda, e incluso su sola presencia es justamente la condición del individualismo, que a su vez es la negación de la intersubjetividad. La comunidad es la condición de posibilidad de la emergencia individual. El individualismo neoliberal de Bernardo no cancela la relación con el otro, sino que más bien la vuelve perversa. Su asesinato más personal, que sucede cuando purga una condena en prisión, es narrado como una experiencia sexual de absoluto sadismo al ver al otro completamente dominado:

estaba de pie, con la navaja hundida hasta el mango en las entrañas; la sangre, la orina y las fuerzas escapándose de su cuerpo. Por unos segundos contempló el bulto de su rival en el suelo, la cabellera antes rubia ahora sucia de sangre y tierra, y, aún con la piel erizada tras el acceso de placer, soltó el garrote y llevó las manos a la navaja. (267) 
La mención de fluidos corporales y las figuras de la navaja y el garrote, ambos símbolos y prolongaciones fálicas, configuran el odio hacia el otro hombre no solo como una experiencia de expulsión, sino también como un evento íntimo, casi sensual y homoerótico. Es decir, justo donde el machismo y la violencia asesina parecen encontrar su expresión más extrema, que es en la aniquilación del otro, se abre la posibilidad de una experiencia sensorial íntima, física y ontológica. Esto problematiza el acto criminal masculino como un evento de absoluta autoafirmación machista. La frase "nada como matar a un hombre" esconde, en resumen, una paradoja argumental propia de lo masculino y su empeño imposible de una articulación totalizadora y estable del yo: por un lado, es el aserto del sujeto machista a través de la violencia y, por el otro, es también su cancelación en un homoerotismo involuntario —o tal vez inconscientemente deseado-, surgido al presenciar, tocar y empaparse de la intimidad del otro.

Para que Bernardo expulse a su enemigo de la vida, son necesarias la intimidad y la cercanía más extremas. El medio, por lo tanto, pareciera cancelar la intención, ya que el acto de matar en Bernardo se vuelve una forma perversa de homosocialidad y unión entre criminales. Sin embargo, la comunidad tradicional, enmarcada en las políticas de la amistad antes mencionadas, también queda cancelada en aras del triunfo de una forma perversa de depredación criminal, donde la necesidad del otro solo es posible en tanto que se presagia su aniquilación. Si con Damián la diferencia abismal de clase, informada por el ethos neoliberal, anula cualquier posibilidad de comunión homosocial entre el sicario y su patrón, con los hombres de la cantina, que pertenecen a la misma clase social del sicario, tampoco es posible ningún tipo de contacto que promueva alguna forma de convivencia utópica, y que pueda ser simbolizada como una narrativa fundacional.

El vínculo que unía a los hombres en las representaciones canónicas del cine mexicano, transcurridas en cantinas festivas e iluminadas, se transforma en un anti-vínculo agresivo; en una resistencia feroz y una ojeriza hacia el otro producto del individualismo radical 
y de la subjetividad neoliberal depredadora que describen Valencia y Dardot. Bernardo, desde su solitaria mesa en un rincón, entiende la dinámica híper machista y criminal que permea la cantina y constata, con placer perverso, cómo un grupo de hombres se aprovechará de otros cuando abandonen el lugar sin la más mínima intención de intervenir ni de prevenir a las futuras víctimas. La sociedad homosocial ha experimentado la caída edénica, y no hay forma posible de reconstruir el locus amoenus perdido, por lo que la única forma de sobrevivir, para él, consiste en enarbolar una subjetividad depredadora, identificándose con los verdugos y justificando la mala suerte de las futuras víctimas como resultado de un orden social y natural en que sobreviven los más fuertes.

\section{HOMOFOBIA Y MASCULINIDAD AMENAZADA}

El tema de la violencia en Nostalgia de la sombra ha sido uno de los más comentados por los críticos. Ignacio Sánchez Prado argumenta que gran parte de la originalidad de la novela radica en que no presenta la violencia desde un punto de vista moralista, como el gran otro que es necesario dominar o exorcizar, sino como "a social code that enters the urban environment as a strategy of social relationships and as a component of subjectivity" (Amores Perros 46). Herman Herlinghaus reflexiona sobre la radicalidad ética y estética de la novela en el marco de las narco narrativas de México y Colombia. El autor alemán sugiere que Nostalgia "is a rigorous aesthetic move that ... advances to the point at which empathy becomes entirely alien" (85). También la considera una obra post-trágica, ya que la novela no pretende la catarsis ni la domesticación introspectiva del mal, sino más bien el extrañamiento ante la violencia (87). Mi postura difiere ligeramente de estas lecturas, pues si bien concuerdo en que la novela muestra la violencia como un componente subjetivo de relaciones sociales, creo que no por ello cancela la empatía ni mucho menos se aleja de un campo semántico moralizante. Hay que tomar en cuenta que la nove- 
la es, en muchos sentidos, como sugiere Diana Palaversich, una obra neocostumbrista (10). Aunque Palaversich no explica ni desarrolla el concepto, se puede inferir que entiende por ello la exploración y representación de los usos, costumbres, decires y formas de sentir de personajes y arquetipos populares (Moriuchi 2). Bernardo, como el arquetipo del sicario, estaría moldeado a partir de otros tipos regionales norteños como lo son los vaqueros, los hombres de negocios y los narcotraficantes, todas figuras híper masculinas capitalistas y además moralizantes, ya que pregonan comportamientos considerados como correctos sobre otros considerados incorrectos. Representar los usos y costumbres a la par que los tipos sociales, implica por ende una reflexión, ya sea implícita o explícita, sobre el terreno de lo moral, sobre las normas sociales que guían la conducta de los personajes-tipo, sobre la manera en que justifican esa conducta y los límites de esta, espacio minado por prohibiciones y fobias.

Bernardo, como perteneciente a este tipo social que es el sicario moderno mexicano, moldeado a partir de los mencionados tipos de carácter regional, se apega a un ethos masculinista donde reina el machismo, la agresión y la homofobia, siendo este último un fenómeno estrictamente moralizante, ya que el homófobo considera a los hombres homosexuales como anormales, abyectos o depravados, conducta que debe rechazar todo hombre heterosexual tradicional. Según De la Mora, la masculinidad mexicana necesita de la figura del hombre homosexual para afirmar su hegemonía heteronormativa y machista (133). Considero que la homofobia no es exclusiva del machismo mexicano, sino que más bien forma parte del machismo latinoamericano en general e inclusive occidental, fuertemente influido por la moral judeo-cristiana que rechaza de manera rotunda la homosexualidad. Hay que añadir, además, que el proceso mismo de formación de identidad, sea sexual, racial, nacional o de cualquier otro tipo, implica pensar y construir un "otro" (Moriuchi 3). En el caso de la identidad heterosexual occidental, la mujer, los hombres homosexuales y hombres pertenecientes a otras razas o clases socia- 
les han ocupado la figura del "otro". De ahí que, en la masculinidad mexicana, pariente cercana de la masculinidad occidental en general, la homofobia sea una estrategia de poder que intenta sellar la identidad heterosexual y eliminar sus naturales fisuras.

Bernardo, al atravesar el umbral de violencia asesina, se convierte en víctima y emisario de valores e ideas de género que lo trascienden y que implican la afirmación histérica no sólo de la heterosexualidad, sino también de la híper masculinidad. La oportunidad de reafirmar la frontera entre lo propio e impropio de su nueva masculinidad híper violenta se presenta cuando, luego de asesinar a los ladrones, se refugia en un parque frecuentado por hombres homosexuales, donde queda inconsciente por varios días debido a sus heridas. Al despertar, de noche, se da cuenta de que su ropa está llena de mugre y sangre coagulada. Un hombre homosexual le ofrece ayuda. Bernardo primero lo ahuyenta con groserías, pero después, al darse cuenta de su apariencia descompuesta, le pide la ropa. El hombre se niega y Bernardo lo ataca a golpes y lo deja inconsciente. Cuando está despojándolo de la ropa, unos transeúntes se acercan. Bernardo entonces, para despistar el robo, le baja el pantalón a su víctima y finge una relación sexual. El contacto con la carne desnuda de la víctima le hace recordar a su esposa, lo cual le provoca una erección involuntaria y el consecuente coraje contra sí mismo y contra el hombre homosexual. Se apodera de él un sentimiento de asco e incomodidad; ha atravesado, sin desearlo, el umbral de lo propio de su nueva masculinidad. Para restablecer sus límites morales, toma una piedra y le asesta un golpe en la cabeza a su víctima.

Las acciones violentas de Bernardo confirman una de las tesis de Domínguez Ruvalcaba en Modernity and the Nation (2007):

Homosociety and homophobia are the two faces of Mexican masculinity. The former corresponds to the desirable man and the latter to his rejection. The two depend on each other, to nurture the content of moral structures and to generate rationales and simulacra of sense to confirm the necessity for patriarchy. (4) 
La homosociabilidad y la homofobia se convierten, en Bernardo, en los motores que articularán la configuración de su nueva masculinidad. Antes del asesinato de los tres asaltantes y del intento de asesinato del personaje homosexual, Bernardo tomaba cerveza en una cantina del centro de Monterrey. Todavía no desarrollaba ojeriza ni fantasías homicidas contra los hombres. En el primer escenario se fomenta y celebra la compañía masculina y la homosociabilidad. En la escena del parque, en cambio, cuando esa cercanía entre hombres se incrementa y amenaza la estabilidad heteronormativa, se rechaza su presencia de forma violenta. La reacción de Bernardo ante el cuerpo desnudo de otro hombre es similar a la reacción de Pancho contra la Manuela en El lugar sin límites (1978), de José Donoso. Si el cuerpo desnudo de un hombre es capaz de generar excitación sexual vicaria, esto significa que en realidad la frontera entre el cuerpo masculino y femenino, debido a su gran cercanía anatómica, más que una separación tajante, es un continuo corporal. Por ello, para reglamentar el deseo que, por naturaleza, pareciera ser más fluido de lo que muestra la concepción rígida judeo-cristiana de este, es necesaria la reiteración normativa. Según Judith Butler:

Sex is a regulatory ideal whose materialization is compelled, and this materialization takes place (or fails to take place) through certain highly regulated practices. In other words, "sex" is an ideal construct which is forcibly materialized through time. It is not a simple fact or static condition of the body; but a process whereby regulatory norms materialize "sex" and achieve this materialization through a forcible reiteration of those norms. That this reiteration is necessary is a sign that materialization is never quite complete, that bodies never quite comply with the norms by which their materialization is impelled. (2)

Para conservar y re-afirmar el yo masculino, Bernardo exorciza y niega su propio deseo mediante la violencia homofóbica, lo cual pone de manifiesto un orden de género y una masculinidad normati- 
va con fisuras, "never quite complete", como argumenta Butler, una masculinidad, en resumen, vulnerable, que necesita constantemente de acciones violentas que la reafirmen y le devuelvan el cierre siempre aplazado. La dinámica es una relación dialéctica imposible de cerrar, entre la vulnerabilidad y el intento casi neurótico por negarla, tema que exploraremos con más detalle en el siguiente apartado.

\section{TIENES MIEDO}

Como argumenté al principio de este ensayo, Bernardo comienza su carrera delictiva al asesinar, en defensa propia, a tres asaltantes en pleno centro de Monterrey, cuando se disponía a regresar a su casa en transporte público después de una larga jornada laboral. De acuerdo con Sánchez Prado, su carrera criminal es producto del crimen mismo y no de motivaciones psicológicas (Amores perros 45). Considero que en realidad sí existe una motivación psicológica anterior al crimen y que tiene relación con discursos, modelos y exigencias de masculinidad hacia los que Bernardo reacciona. El episodio que lo predispone a cometer el crimen sucede cuando Bernardo toma cerveza en una cantina y un viejo vaquero, borracho y con aspecto "de un animal en busca de sangre" (40) lo encara y le dice: "iYa te vi! ¿Eh? ¡Tienes miedo! ¡Ya te vi!” (40). Bernardo abandona la cantina ignorando al borracho, pero sus palabras lo inquietan. En el trayecto hacia la parada del autobús, no deja de pensar en ellas:

Bernardo reconoció el chisporroteo ácido del remordimiento debajo de la lengua. En vez de plantarse en su sitio con firmeza había huido mientras las reclamaciones del cantinero evitaban que el viejo lo persiguiera. Debió encararlo con valor... Pero algo dentro de él se negó a asumir las sandeces del vaquero como agresión... Por la pantalla de su memoria desfilaron entonces su padre y su madre, sus maestros; los árbitros, cuando jugaba futbol americano, el entrenador y los integrantes del equipo rival; 
sus jefes en el trabajo, hasta Victoria. Nunca había hecho nada aparte de dar media vuelta y retirarse. La tibieza, la indiferencia, el conformismo definían su existencia desde muchos años atrás. O el miedo. (48)

Al caminar por las calles del centro de Monterrey en pleno verano, y luego de haber rechazado las insinuaciones sexuales de una tendera que trabajaba en un puesto de comida donde se detuvo a tomar un refresco, Bernardo comienza a obsesionarse con la idea de que siempre ha sido un cobarde. "Tienes miedo. Tienes miedo, resonaba una voz dentro de su cerebro. Te faltan huevos, pinche agachón, vives cagado, no juntas ni valor para jalarte una vieja al hotel, ni cuando se te ofrece en charola" (49). La tensión psicológica que experimenta Bernardo es el resultado de sentir que no está a la altura de un ideario masculino. Si la masculinidad no es solo una esencia, sino una construcción social en constante cambio, y funciona, como apunta Rebecca E. Biron "as an unquestioned ontological guarantor of gendered identity and an unstable, ever-shifting demand for credible performances of that identity" (11), entonces expresar o reconocer la vulnerabilidad es uno de los tabúes de la demanda de credibilidad de la masculinidad hegemónica, entendida como "the masculinity that occupies the hegemonic position in a given patern of gender relations" (Connell 76). La masculinidad hegemónica, más que una realidad, es el ideal de género impuesto culturalmente a los hombres. Una pieza importante de ese ideal es evitar la expresión o el reconocimiento de la vulnerabilidad y el miedo. De ahí que moleste tanto a Bernardo ser increpado por ese hombre, que además es un vaquero norteño híper masculino, es decir, el arquetipo hegemónico por excelencia del hombre norteño. Un hombre vulnerable, débil o con miedo no está a la altura de los requerimientos, discursos, rituales y roles que Bernardo piensa debe cumplir como hombre (credible performance). El reconocimiento del vaquero de esa falla vergonzosa de género - tener miedo- es también un llamado a no tenerlo, o como diría Butler, una reiteración forzada de normas, ya que el performan- 
ce de la masculinidad, cualquiera que esta sea, siempre dependerá de una cultura que codifica e impone esa misma masculinidad.

La antropóloga feminista Rita Segato, en su obra Las estructuras elementales de la violencia (2003), observa, basada en las teorías de Bajtin, que ciertos actos agresivos masculinos, como la violación, tienen un carácter dialógico al ser parte de una relación intersubjetiva de mandatos masculinos de una comunidad de hombres (35). Partiendo de esta idea, se podría decir que la masculinidad en general tiene un carácter dialógico con una comunidad mayor que la hace posible a través de exigencias y normas, aunque en el momento del performance concreto no esté físicamente presente esa comunidad. A estos códigos, normas y mandatos intersubjetivos Segato los llama "panorama mental" (34). Cuando Bernardo se enfrenta a los asaltantes, su panorama mental está fuertemente condicionado por el reconocimiento y rechazo a su cobardía, expuesta por el vaquero híper masculino. La única forma posible de escape, dentro de esa codificación masculina machista, es la violencia. Solo ella puede devolver la masculinidad amenazada a su performance creíble. Cuando los asaltantes golpean a Bernardo y lo tumban al suelo, se activa en él una rabia contenida debido a una vida llena de limitaciones económicas y de pequeñas cobardías. Siente entonces la imperiosa necesidad de deshacerse del miedo y "ser hombre":

Sintió la sangre en ebullición, la ira que le hinchaba el pecho, el nacimiento de una voracidad que no conocía o que había olvidado. Cada uno de sus músculos vibraba, y ese estertor continuo, tan parecido a un ataque, comenzó a generarle en la garganta un bramido animal. Sus miembros eran cables a punto de romperse a causa de la tensión. Los latidos de su corazón le rebotaban en el cráneo. Cuando las manos del que lo registraba palparon el bolsillo donde guardaba los billetes, liberó la energía contenida. (53)

El asesinato de los ladrones, tras una pelea brutal, funciona como un rito de paso en la vida de Bernardo. Este término, acuñado por 
el etnógrafo francés Arnold Van Gannep en su obra Los ritos de paso (2008), se refiere al ritual, generalmente de carácter religioso elaborado por una comunidad en forma de ceremonia, que legitima, guía y prepara a un individuo en el paso de una etapa importante de la vida a otra, como son el matrimonio, el inicio de la adolescencia, el parto, entre otros (16). Mircea Eliade, quien retoma las ideas de Gannep, propone que en un ritual de paso, la iniciación —el momento en que la persona atraviesa ese ritual de paso- provoca "una modificación radical del status religioso y social de la persona... En términos filosóficos, iniciación equivale a una mutación ontológica de la condición existencial. El novicio emerge como un ser completamente distinto; se ha convertido en otro" (69). Aunque en el caso de Bernardo no hay una comunidad que administre el rito de paso, el asesinato de los ladrones guarda similitudes importantes con este por dos razones. En primer lugar, Bernardo experimenta un cambio radical de personalidad, se transforma en otra persona al punto de abandonar a su familia e iniciar una nueva vida. En segundo lugar, el acto violento como ritual de paso será percibido y sentido casi como una experiencia de éxtasis religioso, como una purga del individuo hacia una nueva ontología: "Los latidos eran veloces y Bernardo percibió que también los suyos se aceleraban. Por los muslos le corrían vibraciones que fueron a florecer de golpe en su bajo vientre haciendo que en sus labios se abriera una sonrisa" (54). Sonreír, en una situación de refriega y violencia intensas, donde mata a los delincuentes y al mismo tiempo es mal herido y golpeado por ellos, supone una alteración y transformación de la experiencia del dolor en éxtasis, estado propio de varias experiencias iniciáticas de tipo religioso. Este será el momento clave a partir del cual, el periodista, habitante de los suburbios en una casa de interés social, perteneciente a la clase baja educada en constante aspiración a la aplazada clase media, bajo constantes presiones económicas y el sueño frustrado de ser guionista de cine, se transformará en un asesino implacable: "Aunque todavía sangraban, las heridas cesaron de dolerle, el recuerdo de los rostros llenos de ho- 
rror dejó de molestarlo y, sobre todo, la voz dentro de su cerebro enmudeció. El miedo se había esfumado para siempre" (55). Dentro de la gramática de la masculinidad hegemónica a la que Bernardo aspira, vencer y negar el miedo mediante la violencia, se vuelve uno de los ejes centrales de su configuración. Estos constreñimientos de género ya están en el campo social, Bernardo no los crea, y debido a su situación de vida y a las presiones situacionales que padece, poseen un atractivo difícil de resistir, ya que ceñirse a ellos implicará liberarse de su vida limitada, vulnerable y humillante. Vivir y habitar una idea de valentía - tan celebrada en los narco corridos-, que consiste en no tener miedo a la muerte, y en atreverse a matar y a cometer toda una serie de hazañas épicas, actos brutales y fechorías riesgosas, serán los ejes principales del nuevo momento vital que emprenderá Bernardo. Para ello tuvo que atravesar, vivo, el umbral del peligro extremo, devenido en ritual iniciático, para posteriormente convertirse en sicario.

Cuando Bernardo mata a los ladrones, huye de la escena, corriendo, y se refugia en un parque donde cae desmayado debido a sus heridas. Despierta a la noche siguiente y lentamente comienza a recordar el asalto. En ese momento decide abandonar a su familia y renunciar a las ataduras sociales tradicionales:

Nada como matar a un hombre. Nada. Había sido hecho para eso, ahora lo comprendía. Lo supo el viejo vaquero en cuanto me vio. Un estremecimiento lo hizo sonreír. Ya no soportaría las ataduras. Nada debía pesar en su existencia. Por un segundo pensó en Victoria y en sus hijos, más de inmediato trató de deshacerse de ese pensamiento. No va a ser fácil olvidarlos. Ellos me olvidarán primero. El tiempo lo ayudaría. Y si no, contaba con el alcohol, con las vivencias nuevas, con la distancia. (90-91)

Sin embargo, al negar su miedo y al abandonar a su familia, Bernardo se transforma en un monstruo, ya que la vulnerabilidad, su reconocimiento y codificación, son parte fundamental de la subjetividad humana. Según Judith Butler, "[l]oss and vulnerability seem to 
follow from our being socially constituted bodies, attached to others, at risk of losing those attachments, exposed to others, at risk of violence by virtue of exposure" (20). Pero la vulnerabilidad no solo nos expone a la violencia, sino también a la posibilidad del consuelo, de la empatía y a la comunalidad. Negar que el ser humano es esencialmente intersubjetivo, vulnerable, dependiente y abierto a otros, supone el ejercicio de poder de una lógica masculinista que promueve el individualismo radical neoliberal y su cuestionable sentido de independencia total.

Se podría decir que, de una masculinidad tradicional, Bernardo pasa al régimen de lo que Bonnie Mann llama "masculinidad soberana", encarnada en el hombre que "obeys no law but his own, enjoys an entitlement to act that is unabridged by the rights of others (207). La masculinidad soberana, aunque no es exclusiva del neoliberalismo, podría interpretarse como uno de sus máximos desdoblamientos de género debido a su operatividad anti-comunitaria y al individualismo radical que encarna. En el núcleo de su accionar se encuentra la violencia soberana que, de acuerdo con Achille Mbembe es aquella con "el poder y la capacidad de decidir quién puede vivir y quién debe morir” (20). La masculinidad soberana sería la configuración de género que hace de la violencia asesina uno de sus principales marcos de operatividad, lo que da como resultado la inscripción de su accionar en un régimen de necroempoderamiento: el uso de la muerte y la tortura como estrategias de acumulación de capital. En el caso de Bernardo, sin embargo, en esas "prácticas violentas rentables" (Valencia 51) — que son los asesinatos que comete- se esconde una angustia primigenia de género que busca por todos los medios cerrar la brecha entre el yo (vulnerable) y el super yo masculino, aquel que debe dominar, vencer o por lo menos negar el miedo. El miedo en realidad nunca se ha ido de Bernardo; solo se ha transformado en duelo, insomnio y melancolía. Si bien ya ha vencido los fantasmas de la constante carencia económica, ahora lo visitan otros, los de su conciencia. 
El último asesinato de Bernardo, ya devenido sicario profesional, es el de Maricruz Escobedo. En este asesinato, la transgresión es doble y expande la lógica masculinista de Bernardo, ya que no solo mata a una mujer - único asesinato por encargo del que reniega-, sino que además desobedece a Damián cuando intenta comunicarse con él para cancelar el crimen. La paradoja de la novela es que el momento de máxima transgresión de Bernardo coincide con su retorno al basurero, lo cual podría leerse como una crítica tanto al neoliberalismo como a los diferentes imaginarios masculinistas que este promueve. La novela y Bernardo vuelven al punto cero de su vida de sicario, el basurero, espacio que habitó por algún tiempo antes de convertirse en sicario profesional, especie de umbral entre los asesinatos que comete en defensa propia y los que cometerá por gusto o por un sentido perverso de justicia. El sicariato, finalmente, tampoco generó la ansiada liberación y el sentido de libertad que buscaba. La vulnerabilidad y la angustia, a pesar de haberlas distraído con actos violentos y consumo de alcohol, han permanecido, vigilantes, persistentes, en las capas más profundas de su psique. El verdadero problema, que Bernardo nunca resuelve, implica ser víctima $-\mathrm{y}$ también verdugo- de una dinámica y configuración de género envenenada, de la cual no logra escapar.

En conclusión, Nostalgia de la sombra es una de las novelas mexicanas contemporáneas que mejor explora el cambio de imaginarios de la masculinidad en representaciones culturales. El ensayo se estructuró en cuatro niveles de análisis. El espacio de la cantina abrió el análisis de la masculinidad a partir de sus representaciones en el cine mexicano de la Época de Oro - marcadas por un aura comunitaria producto del ethos postrevolucionario-y de la manera en que evolucionaron estas narrativas hacia formas y representaciones distópicas en el periodo neoliberal. Quedó de manifiesto el contraste entre ambas representaciones y las razones que dieron cuenta del cambio. En el segundo apartado analítico, se exploró la emergencia de una nueva configuración en la subjetividad masculina, encarnada por Bernardo 
- personaje principal de la novela -, cuyo marco operativo abraza y reafirma lógicas neoliberales o de capitalismo gore, basadas en la explotación del otro, la falta de escrúpulos, el fanatismo por la ganancia económica y la violencia devenida estrategia de acumulación de poder y capital. Finalmente, en los últimos dos apartados, se examinó la ambivalencia de género del sicario, ya que no solo es un verdugo despiadado, sino también una víctima de discursos y configuraciones de género específicas, entre las que la violencia es una estrategia de autoafirmación masculina, pero también el enmascaramiento de la vulnerabilidad que permea conductas híper violentas propias de hombres sumidos en estas dinámicas de poder. La tesis central de este artículo estableció justamente que, a pesar de la reproducción de la violencia criminal que convierte a Bernardo en un asesino frío y metódico, este también es un personaje frágil y vulnerable, víctima y verdugo de configuraciones de género que él no controla del todo, puesto que estas nuevas formas de violencia emanan del capitalismo gore y su ethos híper masculino.

\section{BIBLIOGRAFÍA}

Barbero, Martín. De los medios a las mediaciones: comunicación, cultura y hegemonía. Editorial Gustavo Gili, 1987.

Bosch, Lolita. Campos de Amapola: antes de esto. Océano, 2012. Buscaglia. Edardo. Lavado de dinero y corrupción política. Debate, 2015. Butler, Judith. Bodies That Matter: On the Discursive Limits of Sex. Routledge, 1993.

. Precarious Life: The Powers of Mourning and Violence. Verso, 2004.

Biron, Rebecca E. Murder and Masculinity: Violent Fictions of Twentieth Century Latin America. Vanderbilt UP, 2000.

Bush, Doug P. "Rejecting Modernity in Parra's Nostalgia de la sombra”. Hispanófila, vol. 173, ene. 2015, pp. 365-377.

Connell, R. W. Masculinities. University of California Press, 1995. 
Dardot, Pierre, y Christian Laval. The New Way of the World: on Neoliberal Society. Verso, 2013.

Derrida, Jacques. "Politics of Friendship". American Imago vol. 50, no. 3, otoño 1993, pp. 353-381.

Domínguez-Ruvalcaba, Héctor. Modernity and the Nation in Mexican Representations of Masculinity: From Sensuality to Bloodshed. Palgrave Macmillan, 2007.

Eliade, Mircea. La búsqueda. Megalópolis, 1971.

Fallaw, Ben. Cardenas Compromised: The Failure of Reform in Postrevolutionary Yucatán. Duke UP, 2001.

García Reyes, Karina. "Morir es un alivio: 33 narcos explican por qué fracasa la guerra contra la droga". El País, 17 may. 2020, elpais. com/elpais/2020/01/09/planeta_futuro/15785.

Gilly, Adolfo. El Cardenismo: una utopia mexicana. Cal y Arena, 1994.

Gónzalez Rodríguez, Sergio. Los bajos fondos. Cal y Arena, 1989.

Gutiérrez, Laura G. Performing Mexicanidad: Vendidas y Cabareteras on The Transnational Stage. UT Press, 2010.

Guzmán, Nora. "iNada como matar un hombre! La semántica de la violencia en Nostalgia de la sombra de Eduardo Antonio Parra." Revista de Literatura Mexicana Contemporánea, vol. 11, no. 26, 2005, pp. 1013-1020.

Harvey, David. "El neoliberalismo como proyecto de clase". Entrevistado por Elsa Roulet. Iade.org.ar, 13 jun. 2013, http://www. iade.org.ar/noticias/el-neoliberalismo-como-proyecto-de-clase.

Herlinghaus, Hermann. Narcoepics: A Global Aesthetics of Sobriety. Boomsburry, 2013.

Irwin, Robert. Mexican Masculinities. University of Minnesota Press, 2002.

Katz, Friedrich. The Life and Times of Pancho Villa. Stanford UP, 1998.

Knight, Alan. La revolución mexicana: del porfiriato al nuevo régimen constitucional. Fondo de Cultura Económica, 2010.

Mann, Bonnie. Sovereign Masculinity: Gender Lessons From the War on Terror. Oxford UP, 2014. 
Mbembe, Achille. Necropolitica. Melusina, 2011.

Meyer, Lorenzo. La segunda muerte de la revolución mexicana. Cal y Arena, 1992.

Monsiváis, Carlos. Los mily un velorios. Conaculta, 1994.

Moriuchi, Mey-yen. Mexican Costumbrismo: race, society, and identity in nineteen-century art. The Pennsylvania State UP, 2018.

Nadal, Alejandro. "Thatcher y Hayek: la sociedad no existe". La Jornada, 10 abr. 2013, https://www.jornada.com.mx/2013/04/10/ opinion/034a1eco

Naím, Moisés. Illicit. Anchor Books, 2006.

Olcott, Jocelyn. Cardenas Compromised: Revolutionary Women in Postrevolutionary Mexico. Duke UP, 2005.

Palaversich, Diana. "La nueva narrativa del norte: moviendo fronteras en la literatura mexicana". A Quarterly Journal in Modern Literature, vol. 61, no. 1, 2007, pp. 9-26.

Paley, Dawn. Drug War Capitalism. Ak Press, 2014.

Parra, Eduardo Antonio. Nostalgia de la sombra. Joaquín Mortiz, 2002.

Ríos Gascón, Iván. El cine de Carlos Fuentes. Ediciones B, 2017.

Ríos, Viri. "No, no eres clase media". The New York Times, 06 jul. 2020, https://www.nytimes.com/es/2020/07/06/espanol/opinion/clase-media-mexico.html.

Sánchez Prado, Ignacio. "Amores perros: Exotic Violence and Neoliberal Fear." Journal of Latin American Cultural Studies, vol. 15, no. 1, 2006, pp. 39-57.

. Screening Neoliberalism. Vanderbilt UP, 2008.

Segato, Rita. Las estructuras elementales de la violencia: ensayos sobre genero entre la antropología, elpsicoanálisisy los derechos humanos. Universidad Nacional de Quilmes, 2003.

Valencia, Sayak. Capitalismo gore. Melusina, 2010.

Van Gannep, Arnold. Los ritos de paso. Alianza editorial, 2008.

Womack, John Jr. Zapata y la revolución mexicana. SEP / Siglo XXI editores, 1985. 
Zavala, Oswaldo. "Imagining the U.S. -Mexico Drug War: The Critical Limits of Narconarratives." Comparative Literature, vol. 66, no. 3, 2014, pp. 340-360.

Zizek, Slavoj. Sobre la violencia: seis reflexiones marginales. Paidós, 2009. 